\title{
Evolution of Eutectic Spacing During Unidirectional Solidification of Al-Ni Alloys
}

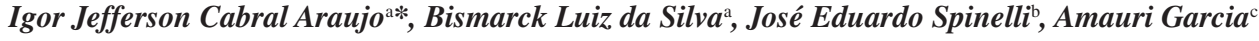 \\ ${ }^{a}$ Department of Materials Engineering, Federal University of Rio Grande do Norte - UFRN, \\ CP 1524, CEP 59072-970, Lagoa Nova Campus, Natal, RN, Brazil \\ ${ }^{\mathrm{b}}$ Department of Materials Engineering, Federal University of São Carlos - UFSCar, \\ Rod. Washington Luis, Km 235, CEP 13565-905, São Carlos, SP, Brazil \\ ${ }^{\mathrm{D}}$ Department of Materials Engineering, University of Campinas - UNICAMP, \\ CP 6122, CEP 13083-860, Campinas, SP, Brazil
}

Received: March 17, 2011; Revised: May 3, 2011

\begin{abstract}
Hypoeutectic Al-Ni alloys show a ductile phase $\alpha$ distributed with a $\beta$ phase $\mathrm{Al}_{3} \mathrm{Ni}$ fragile where $\beta$ serves as reinforcement of the structure of the material. The eutectic composition alloys obey the relationship: $\lambda^{2} . \mathrm{v}=\mathrm{C}$, where $\lambda$ is the eutectic spacing, $\mathrm{v}$ is a tip growth rate and $\mathrm{C}$ is a constant. The aim of this study is to establish correlations between $\lambda$ and $\mathrm{v}$ for hypoeutectic $\mathrm{Al}-1 \%, 3 \%$ and $5 \% \mathrm{Ni}$ alloys. Unsteady-state upward directional solidification experiments were performed, as well as metallography, dissolution of the aluminum matrix and scanning electron microscopy (SEM). The interphase spacing of the three Al-Ni alloys decreased with increasing tip growth rate, with a predominance of a rod-like morphology on intermetallic. It was observed that parameters such as tip growth rate, cooling rate and temperature gradient decreases as the solidification front advances. It was further observed that a single experimental law $\lambda=1.2 \mathrm{v}^{-0,5}$ illustrates the evolution of the interphase spacing for any examined alloy.
\end{abstract}

Keywords: Al-Ni alloys, eutectics, unidirectional solidification, interphase spacing

\section{Introduction}

In order to optimize the properties of aluminum alloys, such as lightness, mechanical strength and corrosion, it is necessary to study characteristics such as microstructural aspect, dendrite arm spacing and porosity, and their evolution during the solidification process ${ }^{1}$.

In the particular case of Al-Ni alloys, within the range of hypoeutectic compositions, the solidification microstructure is composed of a dendritic matrix rich in aluminum $(\alpha)$ surrounded by a eutectic mixture $\alpha+\beta$, where $\alpha$ is rich in aluminum and $\beta$ is enriched by the intermetallic $\mathrm{Al}_{3} \mathrm{Ni}$, with a predominance of a rodlike morphology ${ }^{2,3}$. Such eutectic mixture nucleate in a cooperative and alternative way during growth and remains located between the dendritic arms. The measurement of the interphase spacing is commonly used to quantify the eutectic arrangement along foundry components. Both dendritic arrangement and eutectic mixture configuration can affect the mechanical properties of the mentioned alloys.

The variation of interphase spacing $(\lambda)$ is commonly expressed by the classic relationship for growth of eutectic systems proposed by Jackson and Hunt ${ }^{4}$, as shown in Equation 1, where $\mathrm{v}$ is tip growth rate and $\mathrm{C}$ is a constant.

$$
\lambda^{2} \times \mathrm{v}=\mathrm{C}
$$

The unsteady-state regime of solidification in casting alloys has been the object of extensive studies ${ }^{5,6}$, but there is a lack of studies that emphasize the solidification transient heat extraction, which is close to the industrial reality. Most of the solidification studies use a Bridgman device which promotes steady-state regime ${ }^{2,3}$.

The evolution of the interphase spacing of Al-Fe hypoeutectic alloys under both steady-state and unsteady-state conditions was investigated in a recent study. Two experimental relations have been proposed $^{7}$, as shown in Equation 2. In this case, the eutectic mixture was examined within intercellular regions once cellular structures prevailed in all examined Al-Fe alloys.

$$
\lambda=1.6 \times(\mathrm{v})^{-1 / 2} \text { and } \lambda=3.8 \times \mathrm{G}^{-1 / 2} \times \mathrm{v}^{-1 / 4}
$$

This study aims to determine the solidification thermal parameters (tip growth rate $-\mathrm{V}_{\mathrm{L}}$, temperature gradient $-\mathrm{G}_{\mathrm{L}}$ and cooling rate - $\stackrel{+}{T}$ ), interphase spacing and the resulted interrelations between these experimental data. The solute concentration was varied $(1.0,3.0$ and $5.0 \mathrm{wt} .(\%) \mathrm{Ni})$ to evaluate the effect of the solute content in the interphase spacing. The applicability of the expression proposed by Jackson and Hunt ${ }^{10}$ has been checked for a wide range of solidification conditions.

\section{Experimental Procedure}

Directional solidification experiments with hypoeutectic Al-Ni alloys (1.0, 3.0 and $5.0 \mathrm{wt}$. (\%) Ni) were carried out in a water-cooled solidification apparatus, which is characterized by unsteady-state heat flow conditions, as described in a previous study 9 .

In the unsteady-state solidification system, heat is directionally extracted only through a water-cooled bottom made of low carbon steel (SAE 1020), promoting vertical upward directional solidification. A stainless steel split mold was used having an internal diameter of $60 \mathrm{~mm}$, a height of $157 \mathrm{~mm}$ and a wall thickness of $5 \mathrm{~mm}$.

The Al-Ni partial phase diagram was also computed by ThermoCalc(Thermo-Calc software is an exclusive copyright property of the STT Foundation (Foundation of Computational Thermodynamics, Stockholm, Sweden)) and it is shown in Figure 1. 


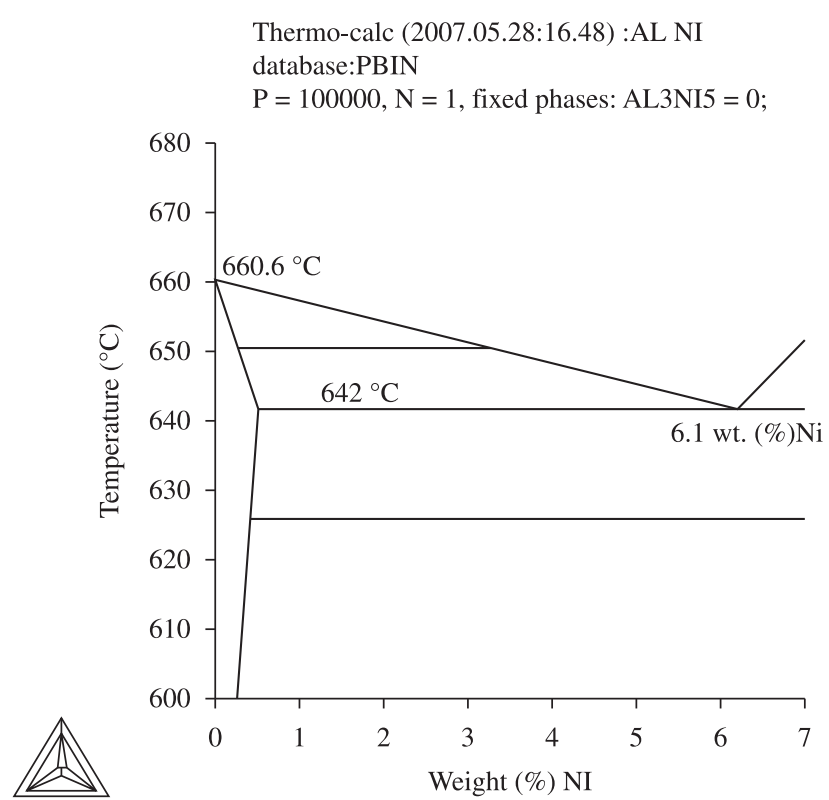

Figure 1. Al-Ni partial phase diagram furnished by the software ThermoCalc $\mathrm{AB}$, version $\mathrm{N}$.

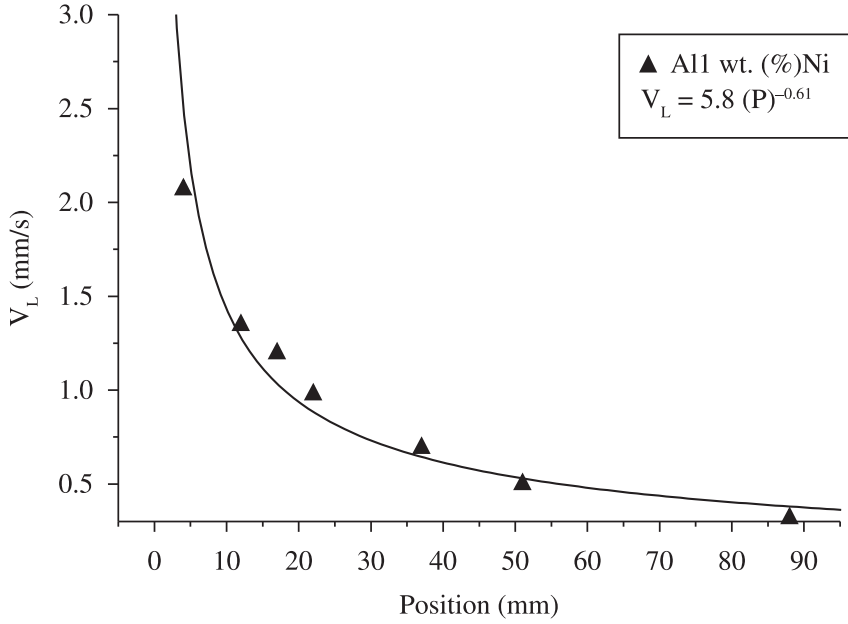

(a)
Continuous temperature measurements in the casting were monitored during solidification via the output of a bank of fine type-K thermocouples (made from $0.2 \mathrm{~mm}$ diameter wire), sheathed in $1.6 \mathrm{~mm}$ diameter stainless steel tubes and positioned at $4,8,12,17,22,37,52$ and $88 \mathrm{~mm}$ from the heat-extracting surface at the bottom. The thermocouples were connected by coaxial cables to a data logger interfaced with a computer, and the temperature data, read at intervals of 0.1 second, were acquired automatically. From these data thermal solidification parameters were inferred $\left(\mathrm{V}_{\mathrm{L}}-\right.$ tip growth rate, $\mathrm{T}^{\circ}$ - tip cooling rate and $\mathrm{G}_{\mathrm{L}}$ - temperature gradient).

After completed the conventional metallography procedures, the microstructures were revealed along the transverse sections of the castings by both optical microscopy (1000× magnification) and scanning electron microscopy (magnification 5000x). The acid solution used to reveal the microstructures was $0.5 \% \mathrm{HF}$ diluted in $\mathrm{H}_{2} \mathrm{O}$, with sample exposure varying from 1 to 10 minutes.

According to literature ${ }^{10}$, the interphase spacings $(\lambda)$ can be measured based on two techniques of quantification: intercept method and triangle method. Böyük and Marasli ${ }^{11}$ claim that more reliable measurements can be obtained in transverse samples. Then, the interphase eutectic spacing was measured by the linear intercept method, with at least 50 measurements for each position.

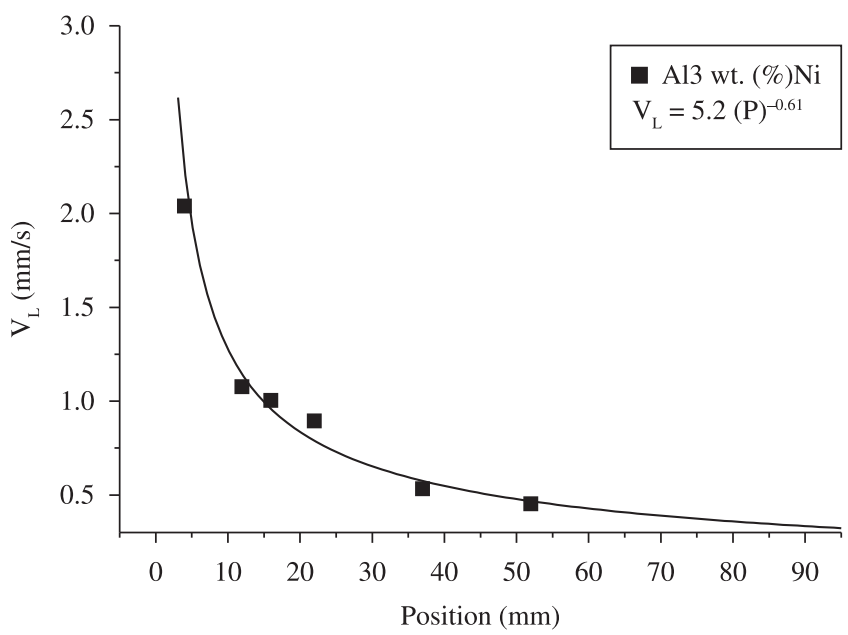

(b)

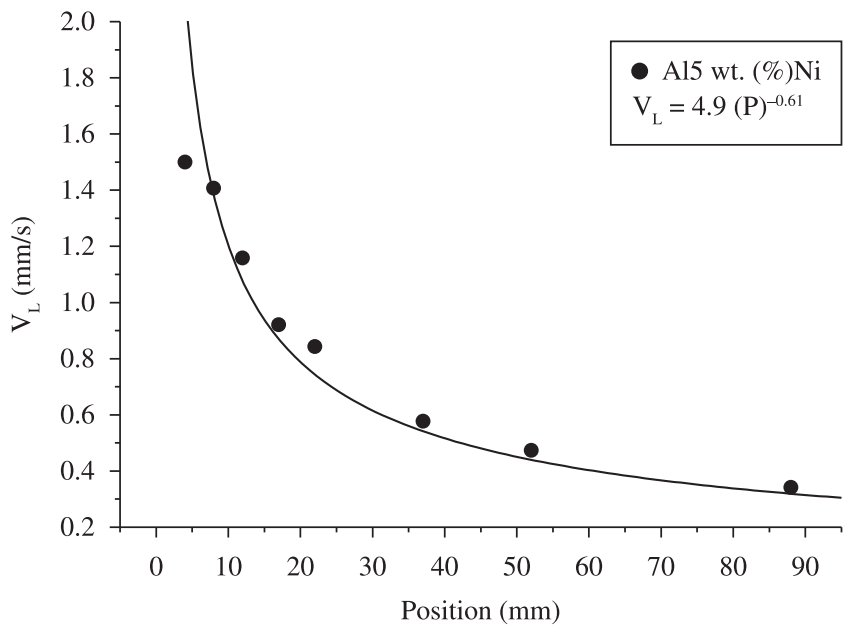

(c)

Figure 2. Tip growth rate evolution for hypoeutectic alloys: a) Al-1 wt. (\%) Ni; b) Al-3 wt. (\%) Ni and c) Al-5 wt. (\%) Ni. 

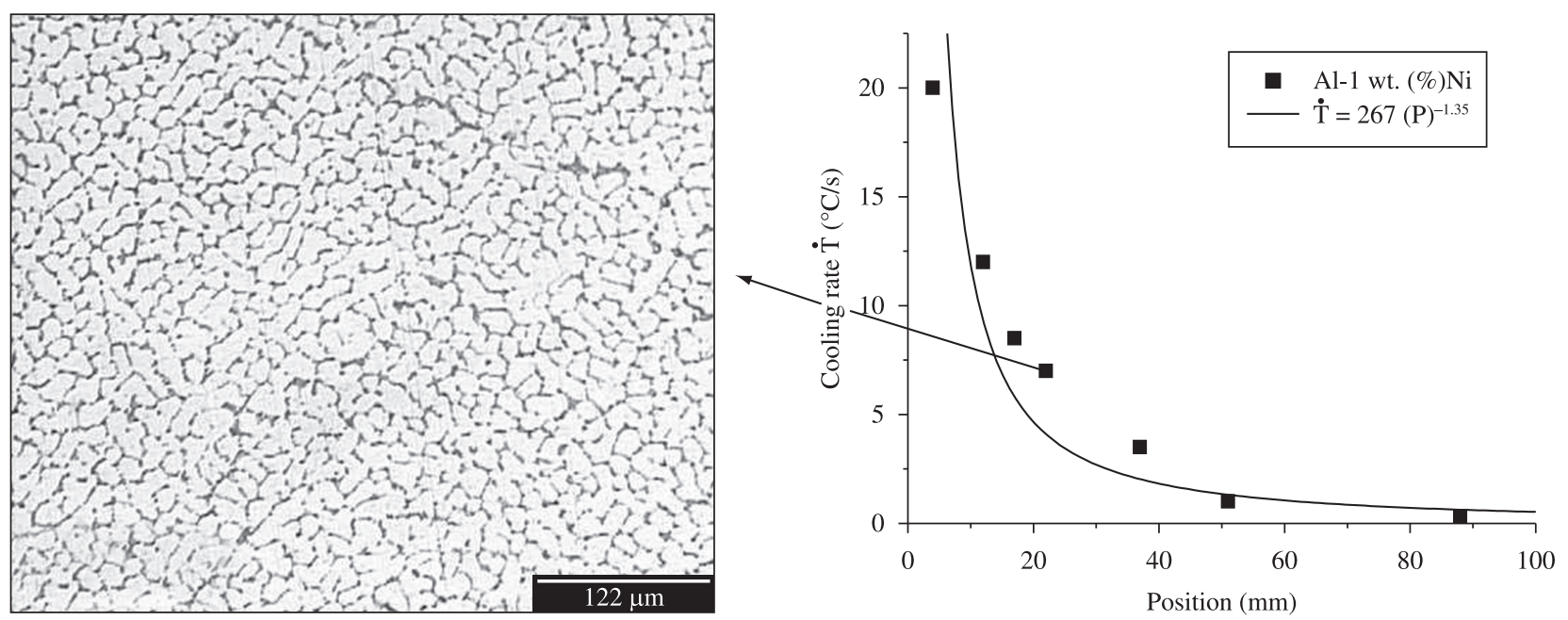

(a)
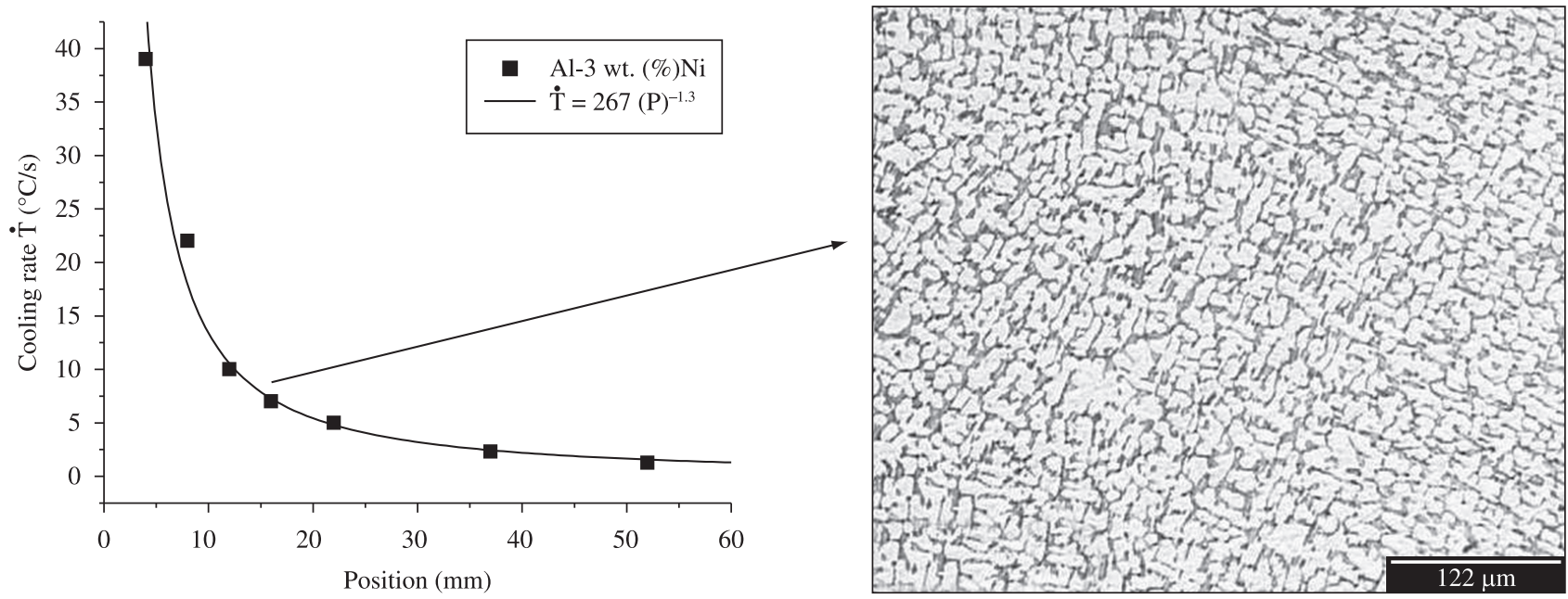

(b)
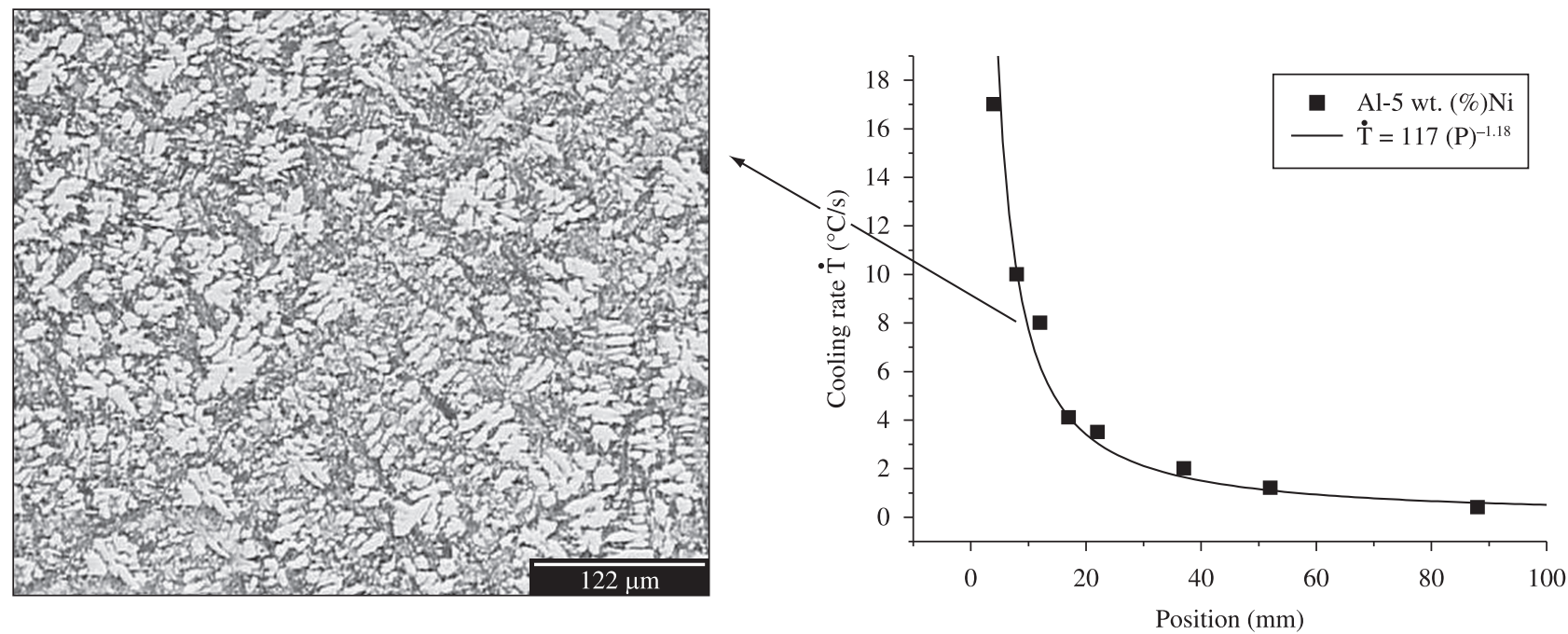

(c)

Figure 3. Cooling rate evolution for hypoeutectic alloys: a) Al-1 wt. (\%) Ni; b) Al-3 wt. (\%) Ni; and c) Al-5 wt. (\%) Ni. The arrows indicate the position in which the microstructure was observed. 


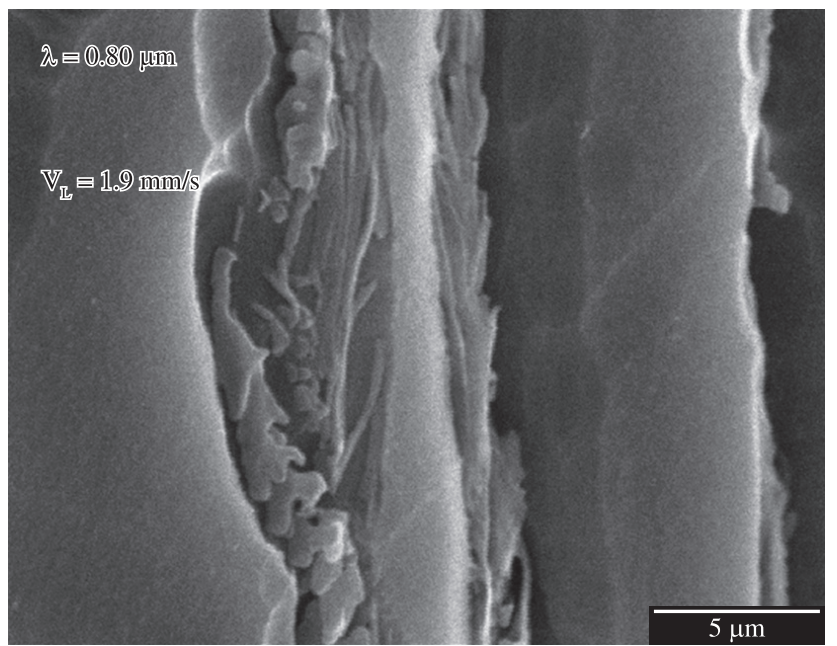

(a)

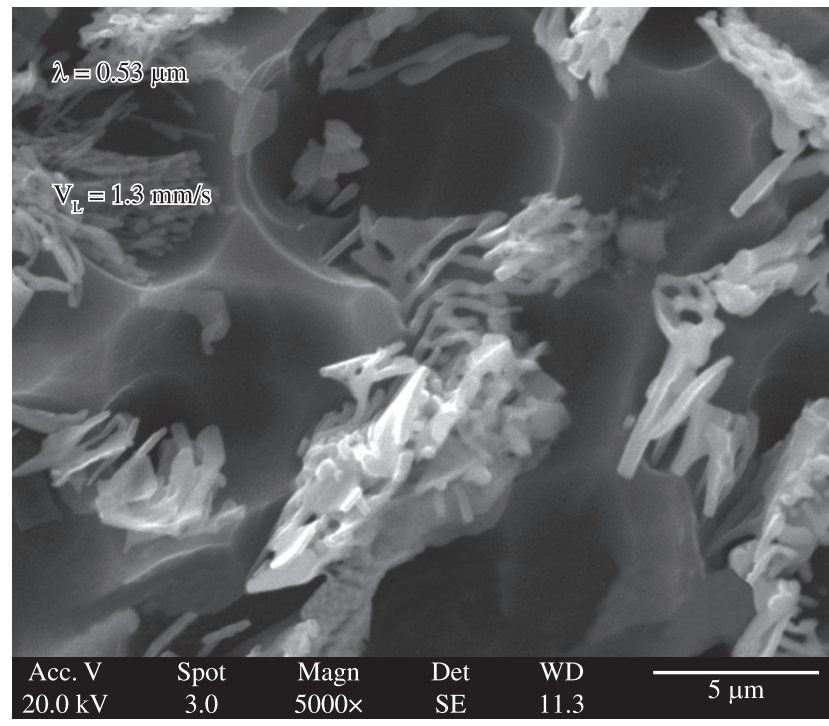

(c)

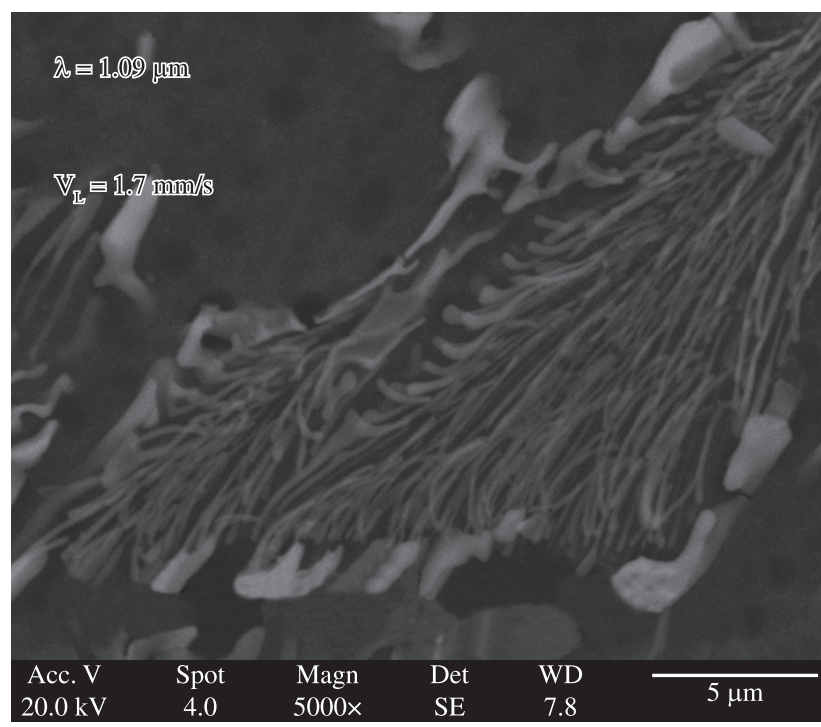

(e)

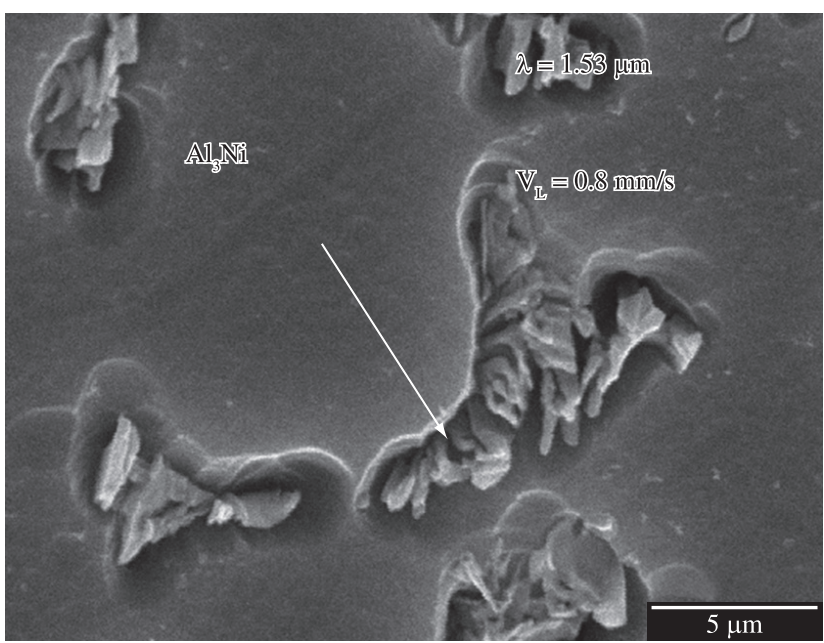

(b)

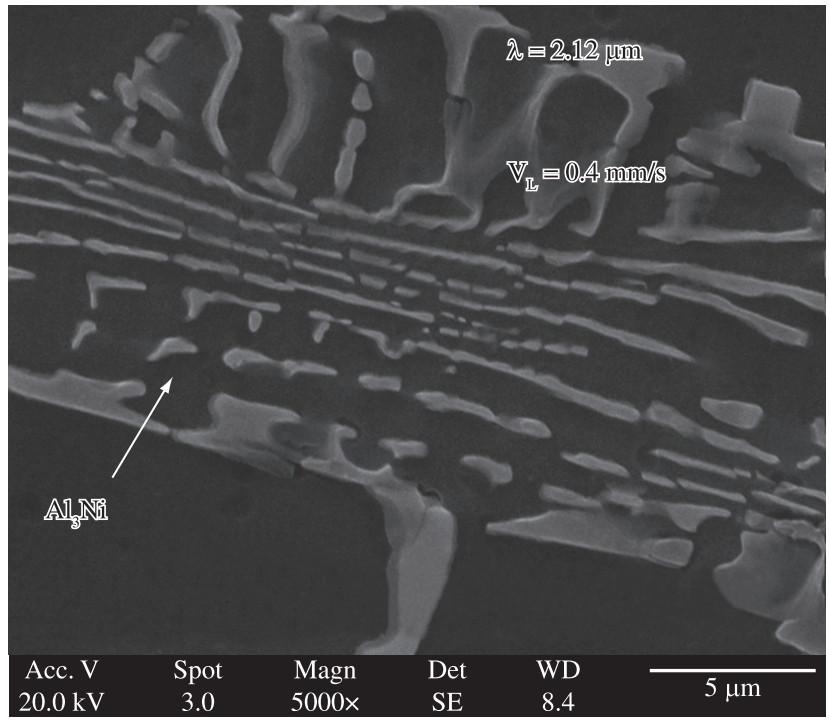

(d)

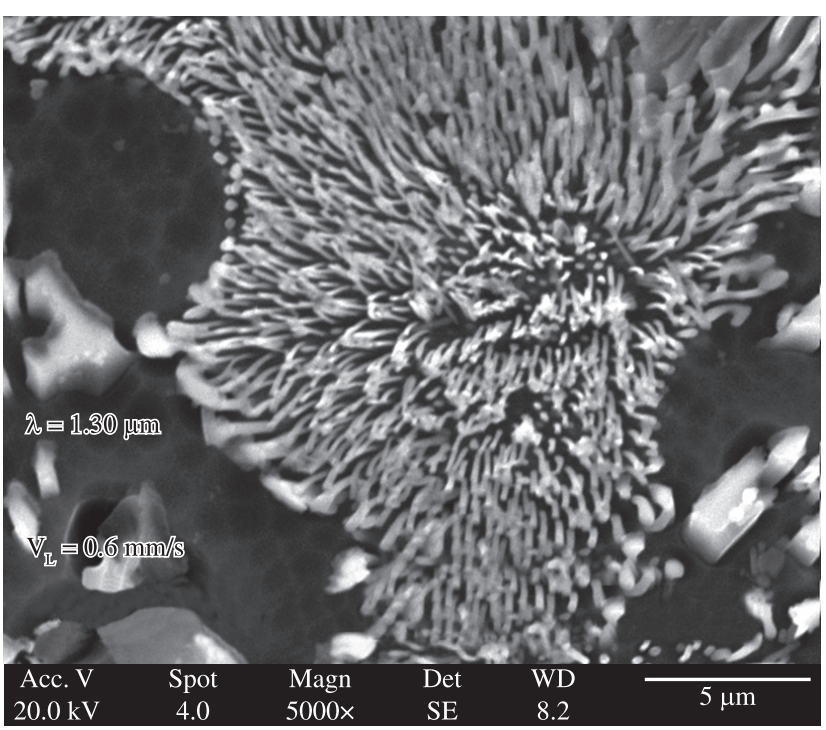

(f)

Figure 4. Typical microstructures of eutectic Al-Ni structures obtained in MEV: a) Al-1 wt. $\% \mathrm{Ni}-\mathrm{P}=5 \mathrm{~mm}$; b) $\mathrm{Al}-1 \mathrm{wt}$. $(\%) \mathrm{Ni}-\mathrm{P}=20 \mathrm{~mm}$; c) Al-3 wt. (\%) Ni - P = $10 \mathrm{~mm}$; d) Al-3 wt. (\%) Ni-P = $60 \mathrm{~mm}$; e) Al-5 wt. (\%) Ni-P = $5 \mathrm{~mm}$; and f) Al-5 wt. (\%) $\mathrm{Ni}-\mathrm{P}=30 \mathrm{~mm}$. P is the position from the metal/mold interface. 


\section{Results and Discussion}

The experimental tip growth rates $\left(\mathrm{V}_{\mathrm{L}}\right)$ were determined for all alloys analyzed by derivative functions of position versus time of liquidus isotherm passage. The values of the liquidus temperatures of the studied alloys can be found in previous study performed by Canté2.

The functions established for position as a function of time were obtained from the intersections of the lines of each liquidus temperature $\left(\mathrm{T}_{\mathrm{L}}\right)$ with the cooling curves for each position of the thermocouples. The cooling rate $(\stackrel{\circ}{T})$ was determined by considering the thermal data recorded immediately after the passing of the liquidus front by each thermocouple. The temperature gradient $\left(\mathrm{G}_{\mathrm{L}}\right)$ was determined according to the ratio of $\stackrel{\circ}{\mathrm{T}}^{\circ}$ and $\mathrm{V}_{\mathrm{L}}$.

The data acquisition system, in which temperature readings are collected at a frequency of 0.5 seconds, permits accurate determination of both the slope of the experimental cooling curves, cooling rate evolution and growth rate.

Figures 2 and 3 show the evolution of $\mathrm{V}_{\mathrm{L}}$ and $\mathrm{T}$ for Al-Ni alloys. As the solidification front advances, the values of both parameters decrease. This effect is reversely translated resulting in increasing of the as-cast microstructure (primary and secondary dendritic spacing) for positions far from metal/mold interface. Typical optical microstructures (transverse sections) can be seen in Figure 3 in order to emphasize the mentioned effect.

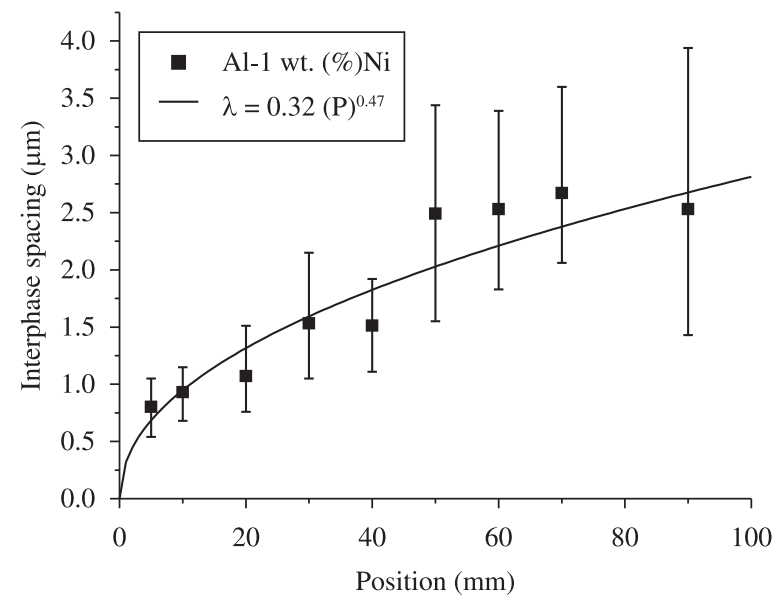

(a)
Figure 4 shows typical SEM images of the interdendritic regions, i.e., emphasizing the eutectic mixture configuration: distribution, size and morphology. It can be noted that the rod-like $\mathrm{Al}_{3} \mathrm{Ni}$ has prevailed. When comparing the microstructures of Figures $4 \mathrm{a}$ and $\mathrm{b}$ (Al-1 wt. (\%) Ni) and the Figures 4e and f (Al-5 wt. (\%) Ni), it can be clearly seen that a higher fiber density was found for the highest amount of nickel, due to the increase of eutectic fraction into interdendritic regions with increasing $\mathrm{Ni}$ content.

Figures $4 \mathrm{c}$ and $\mathrm{d}(\mathrm{Al}-3 \mathrm{wt}$. (\%) Ni) show clear distinction with regard to the interphase spacing with larger $\lambda$ values being observed in the case where the value of $V_{L}$ is lower (Figure $4 d$ ).

Based on images obtained by SEM and optical microscopy several measurements were performed in order to determine the interphase spacings along the Al-Ni castings. The average, maximum and minimum $\lambda_{1}$ values are shown in Figure 5. A single experimental law, Equation 3, is able to represent the evolution of the interphase spacing for all examined Al-Ni alloys with $\mathrm{V}_{\mathrm{L}}$, as shown in Figure 6.

$$
\lambda=1.2 \times\left(\mathrm{V}_{\mathrm{L}}\right)^{-1 / 2}
$$

This means that the increase in the solute content does not affect the interphase spacing for hypoeutectic Al-Ni alloys. The exponent $-1 / 2$ proposed by Böyük and Marasli ${ }^{11}$ is appropriate to state the unsteadystate growth of the eutectic mixture despite the slight overestimation

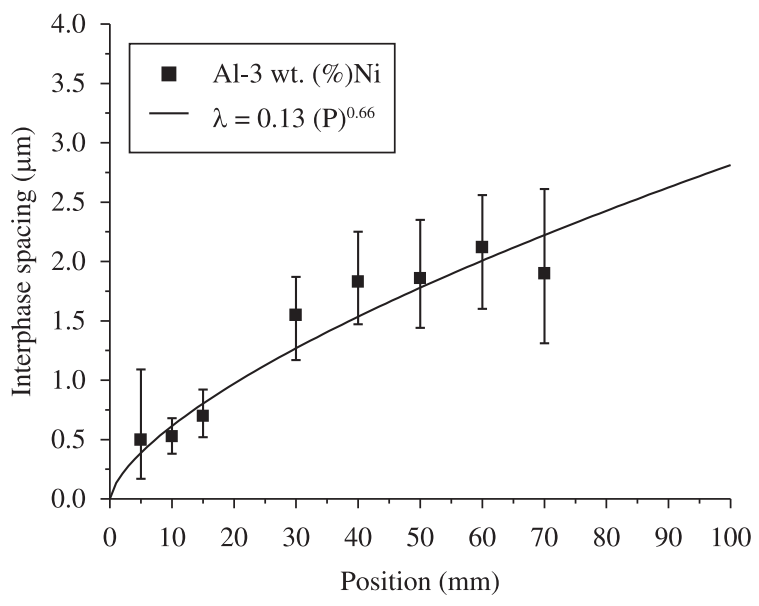

(b)

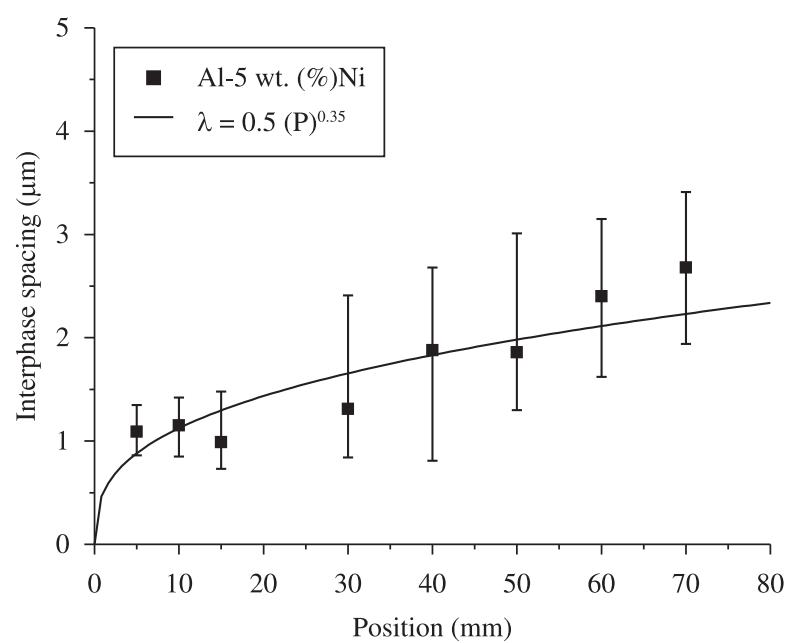

(c)

Figure 5. Interphase spacing evolution as a function of position for: a) Al-1 wt. (\%) Ni; b) Al-3 wt. (\%) Ni; and c) Al-5 wt. (\%) Ni alloys. 


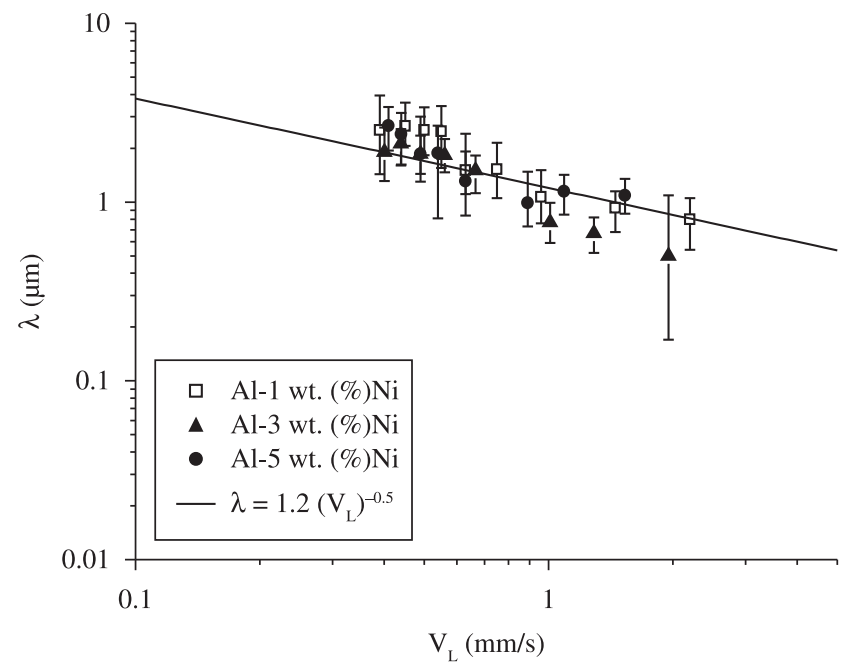

Figure 6. Interphase spacing $(\lambda)$ as a function of tip growth rate $\left(\mathrm{V}_{\mathrm{L}}\right)$.

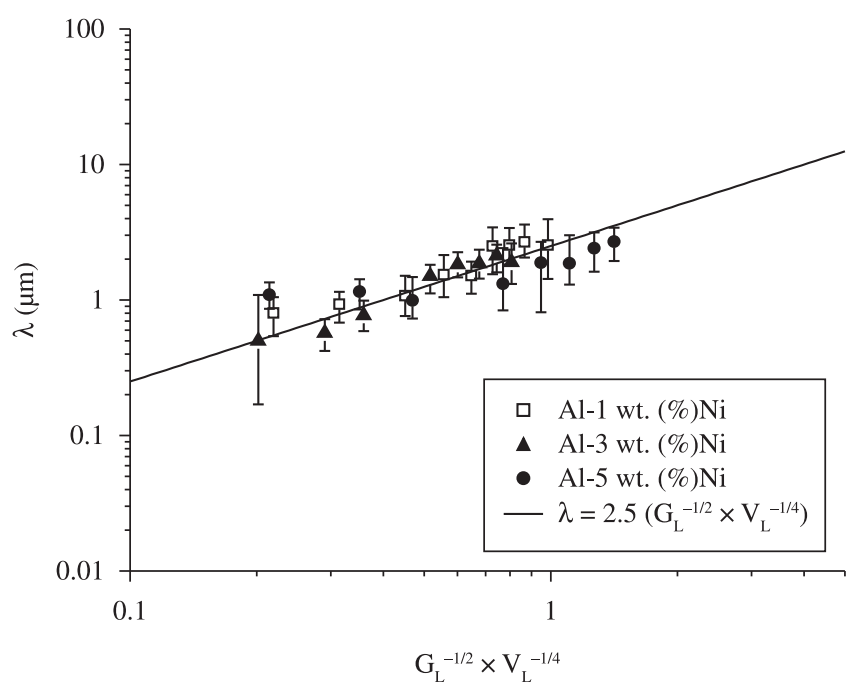

Figure 7. Correlation between $\lambda$ and $\mathrm{G}_{\mathrm{L}}^{-1 / 2} \times \mathrm{V}_{\mathrm{L}}^{-1 / 4}$.

found for three smaller $\lambda$ values of Al-3 wt. (\%) Ni alloy. In addition, higher tip growth rate provides lower interphase spacing values.

Figure 7 shows the mean values of experimental interphase spacings along with minimum and maximum limits measured for the Al-Ni alloys as a function of $\mathrm{V}_{\mathrm{L}}$ and $\mathrm{G}_{\mathrm{L}}$. This relationship is typical for dendritic growth, Equation 4, as proposed by Calberg and Bergman ${ }^{11}$.

$$
\left(\lambda \times v^{\mathrm{a}} \times \mathrm{G}^{\mathrm{b}}=\mathrm{C}\right)
$$

where $\mathrm{a}, \mathrm{b}$ and $\mathrm{C}$ are constants.

Other authors ${ }^{14,15}$ developed expressions for dendritic growth and proposed similar relationships with exponents $-1 / 2$ and $-1 / 4$ for $G_{L}$ and $\mathrm{V}_{\mathrm{L}}$, respectively.

The experimental empirical data fit found in this study (Figure 7) can be considered even better than that found in Figure 6 . This is in agreement with results found by other authors ${ }^{7,8}$ which seems to prove that relate $\lambda$ to more than one thermal solidification parameter may better represent the interphase growth of eutectic mixture for hypoeutectic Al-Ni alloys.

\section{Conclusions}

As the solidification front advances the experimental solidification thermal parameters $\left(\mathrm{V}_{\mathrm{L}}, \mathrm{G}_{\mathrm{L}}\right.$ and $\left.\stackrel{\circ}{\mathrm{T}}\right)$ decrease.
The intermetallic $\mathrm{Al}_{3} \mathrm{Ni}$ prevails with rod-like morphology, and a higher fiber density in the alloys with higher solute content was observed. The spacing $\lambda$ increases as the tip growth rate $V_{L}$ decreases.

A single experimental law: $\lambda=1.2\left(\mathrm{~V}_{\mathrm{L}}\right)^{-1 / 2}$ can be applied to encompass the evolution of the interphase spacing of the three hypoeutectic $\mathrm{Al}-\mathrm{Ni}$ alloys with tip growth rate $\mathrm{V}_{\mathrm{L}}$. It is observed that increase in nickel content does not affect the interphase spacings for these hypoeutectic alloys.

The experimental law: $\lambda=2.5 \mathrm{G}_{\mathrm{L}}{ }^{-1 / 2} \mathrm{~V}_{\mathrm{L}}{ }^{-1 / 4}$ seems to be more appropriate than the first law obtained: $\lambda=1.2\left(\mathrm{~V}_{\mathrm{L}}\right)^{-1 / 2}$. The interrelation between $\lambda$ and more than one solidification thermal parameter seems to be more representative of the eutectic growth in hypoeutectic Al-Ni alloys.

\section{Acknowledgements}

The authors acknowledge the financial support provided by FAPESP (The Scientific Research Foundation of the State of São Paulo, Brazil), CNPq (The Brazilian Research Council) and FAEPEX - UNICAMP.

\section{References}

1. Quaresma JMV, Santos CA and Garcia A. Correlation between unsteadyState solidification conditions, dendrite spacings, and mechanical properties of Al-Cu alloys. Metallurgical and Materials Transactions A. 2000; 31(12):3167-3178. doi:10.1007/s11661-000-0096-0

2. Canté MV. Solidificação Transitória, Microestrutura e Propriedades de Ligas Al-Ni. [Tese] Campinas Universidade Estadual de Campinas; 2009.

3. Canté MV, Spinelli JE, Cheung N and Garcia A. The correlation between microstructure and mechanical properties of directionally solidified hypoeutectic Al-Ni alloys. Metals and Materials International. 2010; 16(1):39-40.

4. Garcia A. Solidificação: Fundamentos e Aplicações. Campinas: Editora da Unicamp; 1997.

5. Ferreira IL, Spinelli JE, Pires JC and Garcia A. The effect of melt temperature profile on the transient metal/mold heat transfer coefficient during solidification. Materials Science and Engineering A. 2005; 408:317-325. doi:10.1016/j.msea.2005.08.145

6. Osório WL, Peixoto LC, Garcia LR and Garcia A. Corrosion behavior of hypoeutectic Al-Cu alloys in $\mathrm{H}_{2} \mathrm{SO}_{4}$ and $\mathrm{NaCl}$ solutions. Acta Metallurgica Sinica (English Letters). 2009; 22(4):241-246.

7. Goulart PR, Spinelli JE, Cheung N, Mangelinck-Nöel N and Garcia A. Al-Fe hypoeutectic alloys directionally solidified under steady-state and unsteadystate conditions. Journal of Alloys and Compounds. 2010; 504(1):205-210. doi:10.1016/j.jallcom.2010.05.089

8. Silva AP, Spinelli JE and Garcia A. Microstructural evolution during upward and downward transient directional solidification of hypomonotectic and monotectic Al-Bi alloys. Journal of Alloys and Compounds. 2009; 480:485-493. doi:10.1016/j.jallcom.2009.01.105

9. Ferreira IL, Siqueira CA, Santos CA and Garcia A. Influence of Metal/Mold Heat Transfer Coefficient on the Inverse Macrosegregation Profile of an A16,2wt\% Cu Alloy Unidirectionally Solidified. Materials Science Forum. 2003; 455:728-731. doi:10.4028/www.scientific.net/MSF.455-456.728

10. Çadirli E, Böyük U, Engin S, Kaya H, Marasli N and Ulgen A. Experimental investigation of effect of solidification processing parameters on the rod spacings in the Sn-1.2 wt.\%Cu alloy. Journal of Alloys and Compounds. 2009; 486:199-206. doi:10.1016/j.jallcom.2009.07.027

11. Böyük U and Marasli Y. Dependency of eutectic spacings and microhardness on the temperature gradient for directionally solidified $\mathrm{Sn}-\mathrm{Ag}-\mathrm{Cu}$ lead-free solder. Materials Chemistry and Physics. 2010; 119: 442-448. doi:10.1016/j. matchemphys.2009.09.022

12. Jackson KA and Hunt JD. Lamellar and rod eutectic growth. Transactions of the Metallurgical Society of AIME. 1966; 236:1129-1142.

13. Carlberg T and Bergman A. On the Formation of Irregular Monotectic Structures. Scripta Metallurgica. 1985; 19:333-336. doi:10.1016/0036-9748(85)90325-4

14. Hunt JD. Keynote Address: Cellular and Primary Dendrite Spacings. In: Proceedings of the International Conference on Solidification and Casting of Metals; 1979; London. London: Metals Society; 1979. p. 3-9.

15. Kurz W and Fisher J. Dendrite Growth at the Limit of Stability: Tip Radius and Spacing. Acta Metallurgica. 1981; 29:11-20. doi:10.1016/00016160(81)90082-1 